\title{
Clustering Analysis on Teachers' Perceptions of Mathematics Pedagogical Content Knowledge
}

\author{
Yuan-Horng Lin ${ }^{1, *}$, Yuan-Shun Lee ${ }^{2}$ \\ ${ }^{1}$ Department of Mathematics Education, National Taichung University of Education, Taichung City, Taiwan \\ ${ }^{2}$ Department of Mathematics, University of Taipei, Taipei City, Taiwan
}

Email address:

lyh@mail.ntcu.edu.tw (Yuan-Horng Lin), leeys@go.uTaipei.edu.tw (Yuan-Shun Lee)

*Corresponding author

To cite this article:

Yuan-Horng Lin, Yuan-Shun Lee. Clustering Analysis on Teachers' Perceptions of Mathematics Pedagogical Content Knowledge. American Journal of Applied Psychology. Vol. 5, No. 2, 2016, pp. 6-11. doi: 10.11648/j.ajap.20160502.11

Received: June 30, 2016; Accepted: July 16, 2016; Published: July 19, 2016

\begin{abstract}
The purpose of this study is to cluster the perceptions of mathematics pedagogical content knowledge (MPCK) for teachers. The subject is 259 primary school teachers in Taiwan. This study constructs dimensions of MPCK according to the review and conclusions of literature. The MPCK assessment includes six dimensions, which are mathematics content knowledge (MCK), students' cognition knowledge (SCK), mathematics instruction knowledge (MIK), mathematics instruction practice (MIP), mathematics assessment knowledge (MAK) and teacher professional responsibility (TPR). The MPCK questionnaire is 4-points Likert scale and its reliability and validity are acceptable. Fuzzy clustering is adopted to cluster the subject based on these six dimensions. Results show that all teachers could be properly classified into six clusters. Each cluster has its own features of mathematics pedagogical content knowledge. There are also significantly differences in the dimensional scores among clusters. Besides, teachers who have more years of in-service tend to have higher dimensional scores on MPCK. These results could provide references for cultivating pre-service teachers and professional promotion for in-service teachers. Based on the findings of this study, some suggestions and recommendations are discussed for future research.
\end{abstract}

Keywords: Fuzzy Clustering, Mathematics Pedagogical Content Knowledge, Pedagogical Content Knowledge

\section{Introduction}

Educational studies have indicated that subject matter knowledge is necessary for effective teaching. Many researches have also showed that students' mathematics achievement is attributed to teachers' mathematics instruction knowledge [7, 12]. Therefore, there is widespread agreement that teachers should have special knowledge for teaching mathematics. Following Shulman's original 1986 address discussing pedagogical content knowledge, most researches indicate such knowledge not only exists but also contributes to effective mathematics instruction [18]. Teachers' mathematics pedagogical content knowledge is apparently the most important factor to student learning [5, 14].

In the last decades of the 20th century, the content and the way mathematics is taught are definitely changed from the traditional curriculum. The traditional method of teaching mathematics relies on the assumption that students acquire knowledge and skills by observing a teacher's explanations and practices. Nowadays, learning mathematics is viewed as an active process in which students construct their knowledge by engaging in meaningful and purposeful activities [9]. Most findings from earlier research on the relationships among teachers' mathematical knowledge, their teaching, and student learning indicate connection between teachers' knowledge and student achievement. It shows the role of teachers' mathematics teaching knowledge in their teaching is important. However, some literature indicates the role of teachers' mathematical knowledge in their teaching is not clear [15]. Therefore, clustering on teachers' perceptions of mathematics pedagogical content knowledge to further investigate its features should be prospective. In this study, it aims to investigate primary school teachers' perceptions of mathematics pedagogical content knowledge (MPCK). Questionnaire of MPCK is to evaluate teachers' perceptions. Fuzzy clustering is adopted to cluster the response data of 
perceptions. The optimal clustering could display the features of MPC for each cluster. The relationship between features of MPCK and experience of in-service could be discussed further. Results could be references to promote the professional development of primary school teachers.

\section{Literature Review}

\subsection{Teaching and Learning Mathematics}

It is important to clarify what the teachers need to know and be able to do mathematically in order to be effective in teaching mathematics for understanding [2]. They developed the practice-based theory of for teaching and they clarified [1].

In addition to general pedagogical knowledge and knowledge of the content, teachers need to know things like what topics children find interesting or difficult and the representations most useful for teaching a specific content idea. Pedagogical content knowledge is a unique kind of knowledge that intertwines content with aspects of teaching and learning (p. 4).

An understanding of the different kinds of perspectives that mathematics teachers hold on teaching mathematics can help to highlight some of the key characteristics of instructional practices that teachers' professional development aim to support.

Many definitions of pedagogical content knowledge begin with L. S. Shulman when he stated that pedagogical content knowledge in one's subject area [19]. As L. S. Shulman stated [20].

The key of distinguishing the knowledge base of teaching lies at the intersection of content and pedagogy, in the capacity of a teacher to transform the content knowledge he or she possesses into forms that are pedagogically powerful and yet adaptive to the variations in ability and background presented by the students. (p. 15)

An argument that highlights the role of mathematics teachers in promoting educational improvement can be found in the research on school leadership. School leaders are increasingly considered as mediators of policies to support teachers' professional development of mathematics instruction [6]. Frameworks on teacher knowledge for mathematics teaching create a foundation for educational researchers who investigate the interaction of knowledge occurring in the classroom. The knowledge is multifaceted practice which is a challenge to decompose, evaluate and analyze the type of mathematics pedagogical knowledge.

Since teachers' mathematics knowledge greatly becomes an important issue throughout the past several decades, numerous approaches and methodologies have been undertaken in an attempt to identify the relationships among teachers' mathematics knowledge and student learning [16]. Studies using proxy measures have been mainly sought to demonstrate a relationship between teachers' demographic variables and teachers' mathematical knowledge. Another studies using direct measures to assess teachers' mathematics knowledge consider teachers' knowledge will influence student achievement [12]. Another lines concerning teachers' effectiveness tend to investigate and observe teachers' mathematical knowledge while they are teaching [10]. This study adopts clustering analysis to reveal the features of teachers' mathematical knowledge should be a prospective approach.

\subsection{Dimensions of Knowledge for Mathematics Instruction}

L. S. Shulman and P. L. Grossman refined the concept of pedagogical content knowledge and developed five subcomponents: knowledge of alternative content frameworks, knowledge of student understanding and misconceptions of a subject, knowledge of curriculum, knowledge of particular content for the purpose of teaching, and knowledge of topic specific pedagogical strategies [21]. In accordance with this point, one is clearly understood what knowledge mathematics teachers' should have.

Several other scholars have also attempted to identify components of teacher mathematics knowledge. To summarize the viewpoints, their common suggested components include four categories of knowledge: knowledge of mathematics, context specific knowledge, pedagogical knowledge, and knowledge of learners' cognition in mathematics [8]. In addition, mathematics teachers' beliefs are partly of their components [23]. Besides, the above four components of teachers' knowledge each influences one another.

P. Mishra and M. Koehler considered the development of technology had influenced the usage in educational environment, they provided the concept of technological pedagogical content knowledge [17]. The complicated relationships are shown in Figure 1.

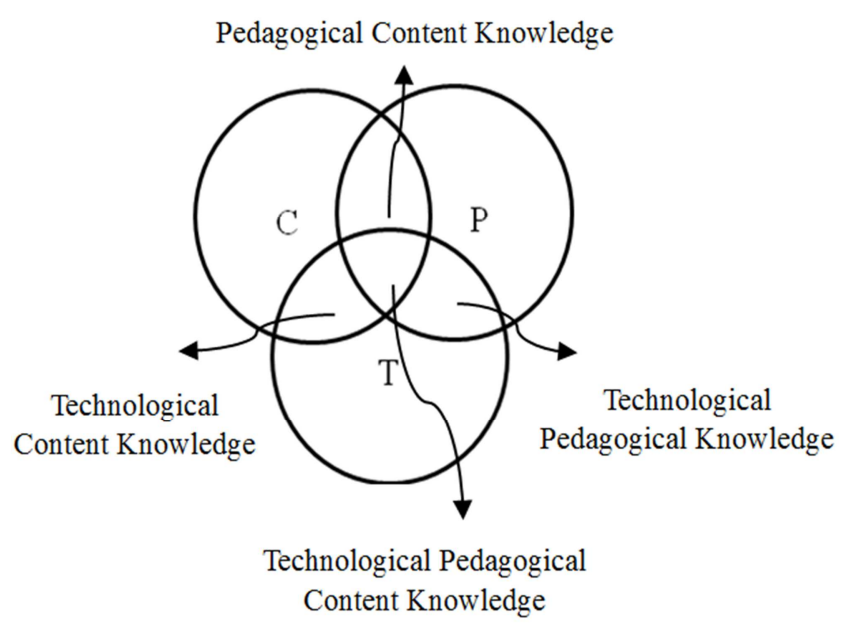

Figure 1. The structure among content, pedagogy and technology (Mishra \& Koehler, 2006, p.1025).

H. C. Hill, D. L. Ball and S. G. Schilling proposed three types of subject matter knowledge (SMK) and three types of pedagogical content knowledge (PCK) [11]. As to mathematics teachers, the knowledge is non-overlapping categories in the domain of mathematical knowledge for teaching. It is shown in Figure 2. 


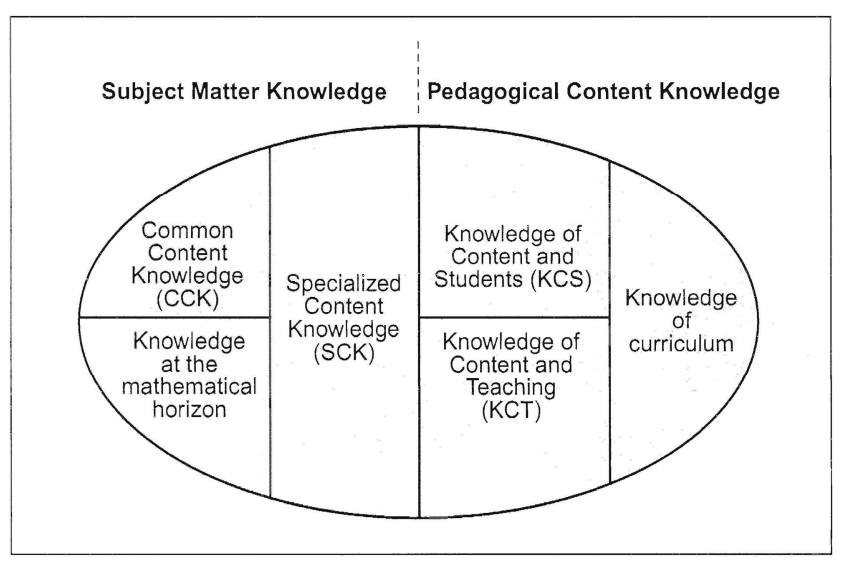

Figure 2. Domain map for mathematical knowledge for teaching (MKT) from Hill, Ball, and Schilling (2008).

Teacher knowledge is strongly related to individual experiences and contexts [25]. A major conclusion from literature is that an understanding of teacher knowledge may be useful to improve teacher professional development and to make educational innovations more successful.

Some literature investigated effects of teachers' mathematical knowledge for teaching on student achievement. H. C. Hill, B. Rowan and D. L. Ball used a linear mixed-model methodology to explore whether and how teachers' mathematical knowledge for teaching contributed to gains in students' mathematics achievement [12]. The data included the first and third graders' mathematical achievement gains over a year which was nested within teachers, who in turn were nested within schools. Results showed that teachers' mathematical knowledge was significantly related to student achievement gains in both first and third grades after controlling for key student- and teacher-level covariates. This finding provided suggestions to improve students' mathematics achievement by improving teachers' mathematical knowledge.

\subsection{Fuzzy Clustering and Its Application in Education}

L. A. Zadeh developed fuzzy theory and it flourished methodologies in many fields. In recent years, fuzzy theory has became one approach of data analysis methodology [4, 27]. Suppose $A$ is a fuzzy set and $\mu_{A}$ is membership function with the membership value $0 \leq u_{A}(x) \leq 1, u_{A}(x)$ represents the degree that $x$ belongs to fuzzy set $A$.

The most widely-used fuzzy clustering algorithm is the fuzzy c-means algorithm (FCM). J. C. Bezdek combined fuzzy theory and clustering technique and he innovated fuzzy clustering greatly since he brought the membership into the objective function [3]. This fuzzy clustering is also called fuzzy c-means which allows partial memberships of data points in the clusters. It is suitable to cluster database so that population of dataset could be classified into some subpopulations. Fuzzy clustering is a useful technique which helps to enrich the semantics of the data by revealing patterns in database. For a data matrix $X=\left(x_{n m}\right)_{N \times M}$ with $N$ subjects and $M$ variables, the membership matrix
$U=\left(u_{c n}\right)_{C \times N}$ and the group center matrix $V=\left(v_{c m}\right)_{C \times M}$ are unknown under group number $C$. The following objective function with optimization problem is applied as follows,

$$
J(U, V)=\sum_{n=1}^{N} \sum_{c=1}^{C}\left(u_{c n}\right)^{q} d^{2}(c, n)
$$

where $d^{2}(c, n)=\sum_{m=1}^{M}\left(x_{n m}-v_{c m}\right)^{2}$ and $u_{c n}, v_{c m}$ could be acquired by iteration with convergence.

Decision on number of cluster is the issue of clustering validity. There are some indices to help select the optimal number of cluster. Two popular indices, which are partition coefficient $F(U ; C)$ and partition entropy $H(U ; C)$, are used in this study. The formulas are as follows [3].

$$
\begin{aligned}
& F(U ; C)=\frac{1}{N} \sum_{n=1}^{N} \sum_{c=1}^{C}\left(u_{c n}\right)^{2} \\
& H(U ; C)=\frac{-1}{N} \sum_{n=1}^{N} \sum_{c=1}^{C} u c n \ln (u c n), \forall u c n \neq 0
\end{aligned}
$$

Within the range of possible clustering number, the best partition is that corresponding to the highest partition coefficient. As to the partition entropy, the best partition is that corresponding to the lowest partition entropy [26].

Fuzzy clustering has been adopted to identify and classify at-risk students at an early stage of their academic career so that teachers can develop plans to improve their performance [13]. Those at-risk students were classified into weak, average and good clusters. The findings could help educational managers monitor the performance of various groups of students and improve academic achievement. Clustering analysis was also adopted to investigate the knowledge that experienced science teachers have of models and modelling in science in the context of a school curriculum innovation project in which the role and the nature of models and modelling in science are emphasized [24]. In their study, two instruments of questionnaires are used collect response for clustering analysis. Results showed that different clusters had varieties of the teachers' knowledge of models and modelling in science. H. S. Siller, S. Kuntze, S. Lerman and C. Vogl investigated the big idea on the mathematics classroom for teachers to be aware of this big idea related to a variety of curricular contents. They study concentrated on views of Austrian and German pre-service teachers about the significance of modelling as a big idea. Clustering was adopted to analyze the ratings of the big ideas about results concerning the pre-service teachers' perceptions [22]. Its findings indicated the various features of big idea for different clusters. In according to the above the clustering application in education, it is concluded that clustering analysis should be beneficial to probe the mathematics pedagogical content knowledge of teachers. 


\section{Research Design}

\subsection{Questionnaire of MPCK}

The questionnaire of perceptions of mathematics pedagogical content knowledge (MPCK) is designed by the author according to the related literatures of mathematics teaching knowledge. The questionnaire is four-point Likert scale. The coding and linguistic variables are $1=$ strongly disagree 2 = disagree, 3 = agree and $4=$ strongly agree. In this study, the questionnaire consists of six dimensions. These dimensions are mathematics content knowledge (MCK), students' cognition knowledge (SCK), mathematics instruction knowledge (MIK), mathematics instruction practice (MIP), mathematics assessment knowledge (MAK) and teacher professional responsibility (TPR). The validity has been confirmed based factor analysis and experts. The Cronbach reliability, which is one of internal consistency indices, with respect to each dimension is between 0.81 and 0.90 . It means that the validity and reliability are acceptable.

\subsection{Subject and Sample}

There are totally 259 primary school teachers in Taiwan participating in the study. Of these teachers, there are 73 male teachers and 186 female teachers. The sample distribution is shown in Table 1. It indicates most teachers are located at 6-15 and 16-25 in-service years.

Table 1. Sample distribution for years of in-service.

\begin{tabular}{lll}
\hline Years of in-service & & Size and percent \\
\hline \multirow{2}{*}{ under 15 years } & under 5 years & $33(12.74 \%)$ \\
& 6-15 years & $109(42.09 \%)$ \\
\multirow{2}{*}{16 years and over } & 16-25 years & $94(36.29 \%)$ \\
& 26 years and over & $23(8.88 \%)$ \\
& Total & $259(100 \%)$ \\
\hline
\end{tabular}

\section{Results and Discussions}

\subsection{Statistics Description and Number of Clusters}

Mean and standard deviation of each dimension are depicted in Table 2. It reveals that the lowest mean score is students' cognition knowledge (SCK) but its standard deviation is quite high. On the contrary, the highest mean score is teacher professional responsibility (TPR) but its standard deviation is the lowest. General speaking, the perceptions as to all dimension of MPCK almost locates at "3 = agree".

The average scores of dimensions for each teachers are the raw data for fuzzy clustering. On the process of fuzzy clustering, partition entropy and partition coefficient are used to decide number of $\mathrm{C}$ clusters. As shown in Table 3 , from $\mathrm{C}=2$ to $\mathrm{C}=8$, the largest partition coefficient $(0.889458)$ and the smallest partition entropy $(0.133875)$ occur when it is $\mathrm{C}=6$. Therefore, it means the subject could be properly classified into six clusters.
Table 2. Mean and standard deviation of each dimension.

\begin{tabular}{lll}
\hline Dimensions & Mean & Standard deviation \\
\hline MCK & 3.09 & .47 \\
SCK & 2.90 & .52 \\
MIK & 3.01 & .53 \\
MIP & 3.05 & .47 \\
MAK & 3.04 & .46 \\
TPR & 3.19 & .42 \\
\hline
\end{tabular}

Table 3. Partition coefficient and partition entropy for number of clusters.

\begin{tabular}{ll|l}
\hline Number of clusters & Partition coefficient & Partition entropy \\
\hline 2 & 0.887876 & 0.177530 \\
3 & 0.885784 & 0.193827 \\
4 & 0.865666 & 0.233950 \\
5 & 0.838500 & 0.289340 \\
6 & 0.889458 & 0.133875 \\
7 & 0.805318 & 0.368319 \\
8 & 0.786818 & 0.41664 \\
\hline
\end{tabular}

Since optimal number of clusters is six which are from cluster I to cluster VI, the sample size and percent are shown in Table 4. Cluster III has the largest sample size (84 and $32.43 \%$ ) and cluster I has the smallest sample size (20 and $7.72 \%)$.

Table 4. Sample size and percent of each cluster.

\begin{tabular}{lll}
\hline Cluster & Size & Percent (\%) \\
\hline I & 20 & $7.72 \%$ \\
II & 50 & $19.30 \%$ \\
III & 84 & $32.43 \%$ \\
IV & 42 & $16.22 \%$ \\
V & 29 & $11.20 \%$ \\
VI & 34 & $13.13 \%$ \\
Total & 259 & $100 \%$ \\
\hline
\end{tabular}

\subsection{Description and Characteristics of Clusters}

Based on the results of fuzzy clustering, the cluster centers for each dimension of MPCK are shown in Table 5. Figure 3 displays the line chart of these cluster centers.

According to Table 5, Cluster I have the lowest dimensional scores and the cluster VI has the highest dimensional scores. In Figure 3, the lines across dimensions of MPCK are almost parallel. Hence, it means the dimensional scores almost increase as they are from cluster I to cluster VI. As to the dimensions of mathematics assessment knowledge (MAK) and teacher professional responsibility (TPR), there exist little differences. It reveals that cluster IV has higher MAK and TPR than cluster V. Cluster II also has higher TPR than cluster III.

In comparison with Table 4 and Table 5, one is concluded that cluster III owns the largest sample size among clusters and its scores of cluster center are almost lower than 3 . Therefore, quite a few of teachers perceive that their own mathematics pedagogical content knowledge (MPCK) is not very well. 
Table 5. Cluster center for each dimension of MPCK.

\begin{tabular}{lllllll}
\hline \multirow{2}{*}{ Cluster } & \multicolumn{6}{l}{ Cluster center of dimensions } \\
\cline { 2 - 7 } & MCK & SCK & MIK & MIP & MAK & TPR \\
\hline I & 2.40165 & 2.10935 & 2.15004 & 2.18792 & 2.32038 & 2.64558 \\
II & 2.80715 & 2.30990 & 2.69484 & 2.81075 & 2.76999 & 3.02980 \\
III & 2.89469 & 2.96046 & 2.87068 & 2.89777 & 2.92389 & 2.96455 \\
IV & 3.35836 & 3.06129 & 3.01151 & 3.18929 & 3.24765 & 3.44951 \\
V & 3.48844 & 3.26089 & 3.60954 & 3.37494 & 3.22162 & 3.32958 \\
VI & 3.73809 & 3.52526 & 3.79068 & 3.80906 & 3.73803 & 3.85050 \\
\hline
\end{tabular}

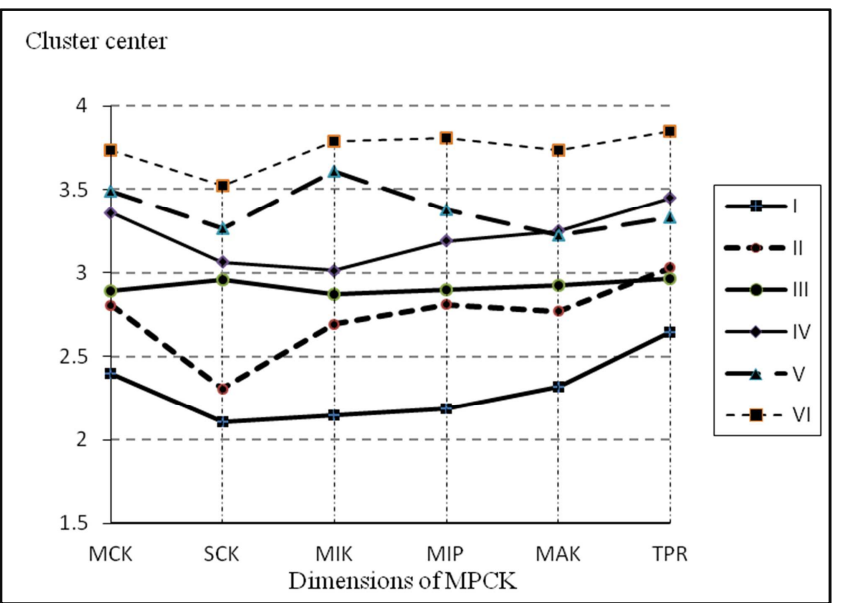

Figure 3. Line chart of cluster center for each dimension.

It is prospective to compare the means of all dimensions among clusters. As shown in Table 6, it clearly displays that there are significant difference on means of all dimensions among clusters.

Table 6. One way ANOVA on dimensions among clusters.

\begin{tabular}{|c|c|c|c|c|c|}
\hline Dimensions & Source & SS & df & MS & $\mathbf{F}$ \\
\hline \multirow{3}{*}{ MCK } & Between Group & 36.56 & 5 & 7.31 & $89.38 * * *$ \\
\hline & Within Group & 20.70 & 253 & .08 & \\
\hline & Total & 57.25 & 258 & & \\
\hline \multirow{3}{*}{ SCK } & Between Group & 47.38 & 5 & 9.48 & $105.16^{* * *}$ \\
\hline & Within Group & 22.80 & 253 & .09 & \\
\hline & Total & 70.18 & 258 & & \\
\hline \multirow{3}{*}{ MIK } & Between Group & 52.18 & 5 & 10.47 & $136.57 * * *$ \\
\hline & Within Group & 19.33 & 253 & .08 & \\
\hline & Total & 71.51 & 258 & & \\
\hline \multirow{3}{*}{ MIP } & Between Group & 42.51 & 5 & 8.50 & $151.96 * * *$ \\
\hline & Within Group & 14.15 & 253 & .06 & \\
\hline & Total & 56.66 & 258 & & \\
\hline \multirow{3}{*}{ MAK } & Between Group & 33.84 & 5 & 6.77 & $78.56^{* * *}$ \\
\hline & Within Group & 21.79 & 253 & .09 & \\
\hline & Total & 55.63 & 258 & & \\
\hline \multirow{3}{*}{ TPR } & Between Group & 30.07 & 5 & 6.01 & $95.61 * * *$ \\
\hline & Within Group & 15.92 & 253 & .06 & \\
\hline & Total & 45.99 & 258 & & \\
\hline
\end{tabular}

$* * * \mathrm{p}<.001$

Further investigation on the cross analysis for cluster and years of in-service is shown in Table 7. The Chi-square test is $\chi^{2}(d f=5)=13.387, p=0.020$. It indicates there exits significantly difference as to frequency distribution. Teachers who are under 15 years of in-service tend to belong to cluster I, II and III. On the contrary, teachers who are 16 years of in-service and over tend to belong to cluster IV and VI. Therefore, one is concluded that teachers who have more years of in-service will have higher scores on all MPCK dimensions. Experienced teachers would have higher perceptions of MPCK.

Table 7. Cross analysis of cluster and years of in-service.

\begin{tabular}{lll}
\hline \multirow{2}{*}{ Cluster } & Years of in-service & \\
\cline { 2 - 3 } & under 15 years & $\mathbf{1 6}$ years and over \\
\hline I & 12 & 8 \\
II & 28 & 22 \\
III & 57 & 27 \\
IV & 17 & 25 \\
V & 15 & 14 \\
VI & 13 & 21 \\
Total & 142 & 117 \\
\hline
\end{tabular}

\section{Conclusions}

This study surveys teachers' perceptions of mathematics pedagogical content knowledge and discuss the clustering based on dimensions of MPCK. Results show the subject could be properly classified into six clusters and perception on dimensions of MPCK varies with clusters. It implies there are some latent subpopulations about MPCK for primary school teachers in Taiwan. Moreover, cross analysis shows primary school teachers in Taiwan who have more years of in-service will have higher scores on all MPCK dimensions. It coincides and induces the finding that experiences of mathematics teaching may influence the perception of MPCK [11]. Conclusions of this study may provide some suggestions for cultivation and professional promotion of primary school teacher. Further research could consolidate quality methodologies to investigate the influential factors in mathematics pedagogical content knowledge.

\section{Acknowledgements}

This research was supported by Ministry of Science and Technology of Taiwan, R. O. C. under grant MOST 103-2511-S-142 -024 -MY3.

\section{References}

[1] Ball, D. L., \& Bass, H. (2003). Toward a practice-based theory of mathematical knowledge for teaching. In B. Davis \& E. Simmt (Eds.), Proceedings of the 2002 annual meeting of the Canadian Mathematics Education Study Group (pp. 3-14). Edmonton, AB: CMESG/GCEDM.

[2] Ball, D. L., Hill, H. C., \& Bass, H. (2005). Knowing mathematics for teaching: Who knows mathematics enough to teach third grade, and how can we decide? American Educator, 14-22, 43-46.

[3] Bezdek, J. C. (1981). Pattern Recognition with Fuzzy Objective Function Algorithm. NY: Plenum. 
[4] Bjelica, M. \& Rankovic, D. (2010). The use of fuzzy theory in grading of students in math. Turkish Online Journal of Distance Education, 11(1), 13-19.

[5] Carpenter, T. P., Fennema, E., Peterson, P. L., CareySource, D. A. (1988). Teachers' pedagogical content knowledge of students' problem solving in elementary arithmetic. Journal for Research in Mathematics Education, 19, 385-401.

[6] Cobb, P., \& Smith, T. (2008). District development as a means of improving mathematics teaching and learning at scale. In K. Krainer \& T. Wood (Eds.), The International Handbook of Mathematics Teacher Education (Vol. 3, pp. 231-254). Rotterdam, The Netherlands: Sense.

[7] Darling-Hammond, L. (2000). Teacher quality and student achievement: A review of state policy evidence. Educational Policy Analysis Archives, 8(1), 1-48.

[8] Fennema, E., \& Franke, M. (1992). Teachers' knowledge and its impact. In D. A. Grouws (Ed.), Handbook of Research on Mathematics Teaching and Learning: A project of the National Council of Teachers of Mathematics (pp. 147-164). New York, NY, England: Macmillan Publishing.

[9] Greeno, J. (2003). Situative research relevant to standards for school mathematics. In J. Kilpatrick, W. G. Martin, \& D. Schifter (Eds.), A Research Companion to Principles and Standards for School Mathematics (pp. 304-332). Reston, VA: National Council of Teachers of Mathematics.

[10] Grossman, P. (1990). The Making of a Teacher: Teacher Knowledge and Teacher Education. New York, NY: Teachers College Press

[11] Hill, H. C., Ball, D. L., \& Schilling, S. G. (2008). Unpacking pedagogical content knowledge: Conceptualizing and measuring teachers' topic-specific knowledge of students. Journal for Research in Mathematics Education, 39, 372-400.

[12] Hill, H. C., Rowan, B., \& Ball, D. L. (2005). Effects of teachers' mathematical knowledge for teaching on student achievement. American Educational Research Journal, 42(2), 371-406.

[13] Inyang, U. G., \& Joshua, E. E. (2013). Fuzzy clustering of students' data repository for at-risks students identification and monitoring. Computer and Information Science, 6(4), $37-50$.

[14] Karaman, A. (2012). The place of pedagogical content knowledge in teacher education. Atlas Journal of Science Education, 2 (1), 56-60.

[15] Mewborn, D. (2001). Teachers content knowledge, teacher education, and their effects on the preparation of elementary teachers in the United States. Mathematics Education Research Journal, 3, 28-36.

[16] Mewborn, D.S. (2003). Teaching, teachers' knowledge, and their professional development. In J. Kilpatrick, W.G. Martin, \& D. Schifter (Eds.), A Research Companion to the Principles and Standards for School Mathematics (pp. 45-52). Reston, VA: National Council of Teachers of Mathematics.

[17] Mishra, P., \& Koehler, M. (2006). Technological pedagogical content knowledge: A framework for teacher knowledge. The Teachers College Record, 108(6), 1017-1054.

[18] Niess, M. L. (2005). Preparing teachers to teach science and mathematics with technology: Developing a technology pedagogical content knowledge. Teaching and Teacher Education, 21(5), 509-523.

[19] Shulman, L. S. (1986). Those who understand: Knowledge of growth in teaching. Educational Researcher, 15(2), 4-14.

[20] Shulman, L. S. (1987). Knowledge and teaching: Foundations of the new reform. Harvard Educational Review, 57(1), 1-22.

[21] Shulman, L.S., \& Grossman, P.L. (1988). Knowledge Growth in Teaching: A Final Report to the Spencer Foundation. Stanford, CA: Standford University.

[22] Siller, H. S., Kuntze, S., Lerman, S., \& Vogl, C. (2011). Modelling as a big idea in mathematics with significance for classroom instruction-How do pre-service teachers see it. In Proceedings of the Seventh Congress of the European Society for Research in Mathematics Education (pp. 990-999).

[23] Thompson, A. (1992). Teachers' beliefs and conceptions: A synthesis of the research. In D. A. Grouws (Ed.), Handbook of Research on Mathematics Teaching and Learning: A Project of the National Council of Teachers of Mathematics (pp. 127-146). New York, NY: England: Macmillan Publishing Co, Inc.

[24] Van Driel, J. H., \& Verloop, N. (1999). Teachers' knowledge of models and modelling in science. International Journal of Science Education, 21(11), 1141-1153.

[25] Verloop, N., Van Driel, J., \& Meijer, P. (2001). Teacher knowledge and the knowledge base of teaching. International Journal of Educational Research, 35(5), 441-461.

[26] Wu, K. L., \& Yang, M. S. (2005). A cluster validity index for fuzzy clustering. Pattern Recognition Letters, 26(9), $1275-1291$.

[27] Zadeh, L. A. (1965). Fuzzy sets. Information and Control, 8, 338-353. 